\title{
Magnitude of the Age-Advancement Effect of Comorbidities in Colorectal Cancer Prognosis
}

\author{
Daniel Boakye, MPHa,b; Viola Walter, MSc, PhDa; Lina Jansen, MSc, PhDa; Uwe M. Martens, MDc; \\ Jenny Chang-Claude, MSc, PhD ${ }^{\text {; }}$, Michael Hoffmeister, MSc, PhDa; and Hermann Brenner, MD, MPH ${ }^{a, e, f}$
}

\begin{abstract}
Background: Comorbidities and old age independently compromise prognosis of patients with colorectal cancer (CRC). The impact of comorbidities could thus be considered as conveying worse prognosis already at younger ages, but evidence is lacking on how much worsening of prognosis with age is advanced to younger ages in comorbid versus noncomorbid patients. We aimed to quantify, for the first time, the impact of comorbidities on CRC prognosis in "age advancement" of worse prognosis. Methods: A total of 4,602 patients aged $\geq 30$ years who were diagnosed with CRC in 2003 through 2014 were recruited into a population-based study in the RhineNeckar region of Germany and observed over a median period of 5.1 years. Overall comorbidity was quantified using the Charlson comorbidity index $(\mathrm{CCl})$. Hazard ratios and age advancement periods (AAPs) for comorbidities were calculated from multivariable Cox proportional hazards models for relevant survival outcomes. Results: Hazard ratios for $\mathrm{CCl}$ scores 1,2 , and $\geq 3$ compared with $\mathrm{CCl} 0$ were $1.25,1.53$, and $2.30(P<.001)$ for overall survival and $1.20,1.48$, and $2.03(P<.001)$ for disease-free survival, respectively. Corresponding AAP estimates for $\mathrm{CCl}$ scores 1,2 , and $\geq 3$ were 5.0 (95\% $\mathrm{Cl}, 1.9-8.1)$, 9.7 (95\% Cl, 6.1-13.3), and 18.9 years $(95 \% \mathrm{Cl}, 14.4-23.3)$ for overall survival and $5.5(95 \% \mathrm{Cl}, 1.5-9.5), 11.7(95 \% \mathrm{Cl}, 7.0-16.4)$, and 21.0 years $(95 \% \mathrm{Cl}, 15.1-26.9)$ for disease-free survival. Particularly pronounced effects of comorbidity on CRC prognosis were observed in patients with stage I-III CRC. Conclusions: Comorbidities advance the commonly observed deterioration of prognosis with age by many years, meaning that at substantially younger ages, comorbid patients with CRC experience survival rates comparable to those of older patients without comorbidity. This first derivation of AAPs may enhance the empirical basis for treatment decisions in patients with comorbidities and highlight the need to incorporate comorbidities into prognostic nomograms for CRC.
\end{abstract}

J Natl Compr Canc Netw 2020;18(1):59-68 doi: 10.6004/jncen.2019.7346

\footnotetext{
aDivision of Clinical Epidemiology and Aging Research, German Cancer Research Center (DKFZ), and ${ }^{b}$ Medical Faculty Heidelberg, Heidelberg University, Heidelberg, Germany; 'SLK-Clinics, Cancer Center HeilbronnFranken, Heilbronn, Germany; ${ }^{d}$ Unit of Genetic Epidemiology, Division of Cancer Epidemiology, German Cancer Research Center (DKFZ), Heidelberg,

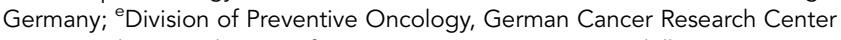
(DKFZ) and National Center for Tumor Diseases (NCT), Heidelberg, Germany; and ${ }^{f}$ German Cancer Consortium (DKTK), German Cancer Research Center (DKFZ), Heidelberg, Germany.
}

\section{Background}

With an approximately $4.4 \%$ lifetime risk, colorectal cancer (CRC) remains the third most commonly diagnosed cancer in the world. ${ }^{1}$ Although prognosis has improved recently, $>40 \%$ of patients with CRC still die within 5 years of diagnosis. ${ }^{2}$ Because of the aging population, the burden of CRC has been predicted to increase in the next decade. ${ }^{3}$

CRC is largely diagnosed at older age, when comorbidities are common. ${ }^{4}$ Some studies have examined the prognostic role of comorbidity in patients with CRC, ${ }^{5-16}$ wherein decreased survival was observed in patients with comorbidities. However, many previous studies could not adjust for important factors such as tumor stage. ${ }^{7,9,11}$ Furthermore, evidence on the role of comorbidities in recurrence-related outcomes is limited. It is also unclear whether the impact of comorbidities varies by tumor stage or site. In some previous studies, the effect of comorbidity on overall survival (OS) appeared to be more pronounced in patients with early-stage CRC, ${ }^{5,14,15}$ but further evidence on other outcomes and from population-based studies is needed for a more comprehensive conclusion regarding the effect of comorbidities on specific patient groups.

Comorbidities and old age independently affect CRC prognosis. Therefore, it is possible that the presence of comorbidities could be associated with worse prognosis at younger ages, but evidence on the "age equivalent" of worsening of prognosis in comorbid compared with noncomorbid patients is lacking. Estimating this could provide valuable information for personalized care and enhanced prediction of prognosis for patients with CRC. The goal of this study was to thoroughly assess the impact of comorbidities on OS and disease-free survival (DFS) in a cohort of patients with CRC and to quantify, for the first time, the "age-equivalent effects" of comorbidities with respect to CRC prognosis.

See JNCCN.org for supplemental online content. 


\section{Methods}

\section{Study Design and Population}

Our study is based on data from 4,602 patients with CRC who were diagnosed in 2003 through 2014 and recruited into the DACHS study, which is an ongoing population-based case-control study in the RhineNeckar region of Germany that was initiated primarily to evaluate the effects of endoscopic screening on CRC risk. Cases are also being followed up to evaluate prognostic factors. Patients with first time diagnosis of CRC (ICD- 10 codes C18-C20) and aged $\geq 30$ years were eligible. Patients were recruited from all 22 hospitals providing first-line treatment of CRC in the study region of approximately 2 million inhabitants. According to estimates from cancer registries, approximately half of the eligible patients were recruited. Further details of the DACHS study have been described elsewhere. ${ }^{17,18}$ The DACHS study was approved by the ethics committees of the Medical Faculty of Heidelberg University and the state medical boards of Baden-Wuerttemberg and Rhineland-Palatinate. All participants provided written informed consent.

At baseline, trained interviewers conducted interviews with participants to collect information on lifestyle factors and medical history. Detailed information on treatment and comorbidities were also recorded in medical records. Follow-up started from CRC diagnosis; vital status and cause of death were ascertained from population registries and public health authorities approximately 3,5 , and 10 years after diagnosis. Information on CRC treatment, newly diagnosed cancers, and recurrence was obtained from physicians approximately 3 years after diagnosis using a standardized questionnaire (physicians abstracted the information from their patient databases). Recurrence history for patients who died during or were lost to follow-up was ascertained from the last attending physician.

\section{Inclusion Criteria}

Because of limited evidence on the impact of comorbidities within tumor stages, our analyses included patients with stage I-IV CRC (UICC stages). ${ }^{19}$ Patients who did not undergo surgery for CRC and those who died within 1 month of surgery were excluded (Figure 1).

\section{Ascertainment of Comorbidities}

ICD-10 codes for comorbidities diagnosed either before or at the time of CRC diagnosis were abstracted from discharge reports. To ensure comparability with previous studies, we used the Charlson comorbidity index (CCI), ${ }^{20}$ adapted by Deyo et al, ${ }^{21}$ to quantify overall comorbidity.

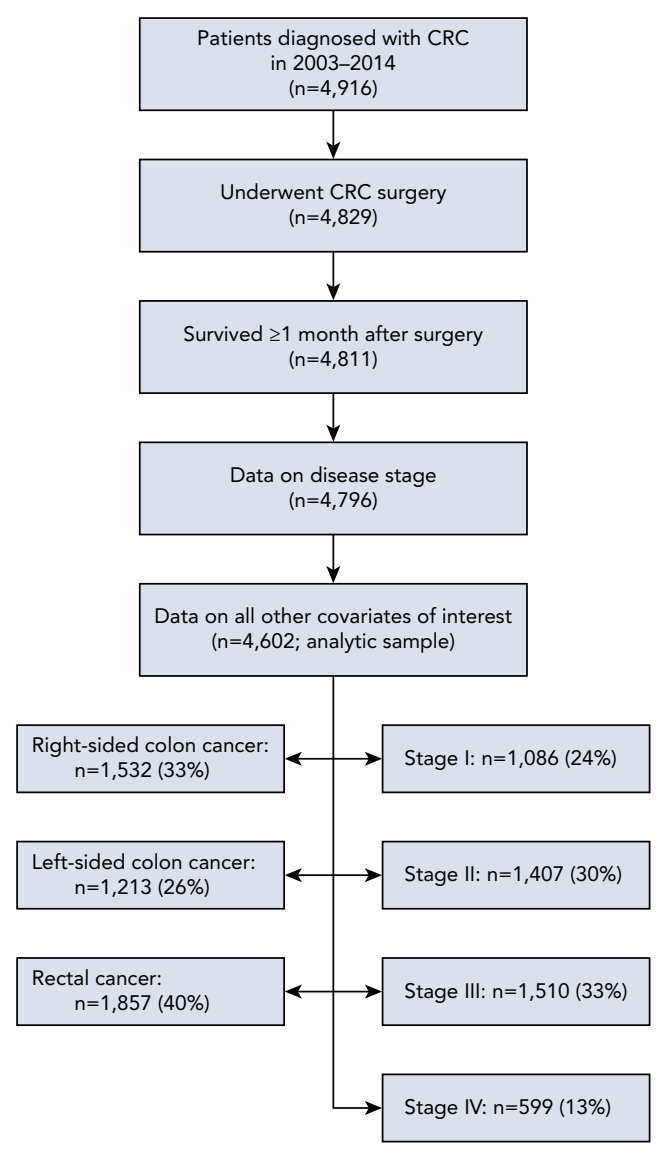

Figure 1. Selection of analytic sample.

Abbreviation: CRC, colorectal cancer.

Briefly, the CCI comprises 19 weighted comorbidities, with weights ranging from 1 to 6 based on the magnitude of the adjusted 1-year mortality risk. ${ }^{20}$ Similar to previous studies, ${ }^{13,16}$ we grouped patients into 4 groups, namely CCI score 0 (no comorbidity), 1,2 , or $\geq 3$ (severe comorbidity).

\section{Statistical Analysis}

We assessed the distribution of the 4 comorbidity groups according to patient and tumor characteristics. Associations of CCI scores with OS (mortality from any cause), CRC-specific survival (CSS; mortality from CRC), non-CRC-specific survival (nCSS; mortality from causes other than CRC), DFS (recurrence of CRC, or mortality from any cause), and recurrencefree survival (RFS; recurrence of or mortality from $\mathrm{CRC}$ ) were examined using Cox proportional hazards regression. Time was estimated from CRC diagnosis to the respective endpoints or end of follow-up, whichever occurred first.

Because participants entered the study at different times, we accounted for specific left-truncation, by 
incorporating "delayed entry time" into the Cox models. Two adjustment levels defined a priori were applied: (1) adjustment for sex, age, tumor stage, tumor site, period of diagnosis, years of school education, smoking status, body mass index (BMI), lifetime physical activity, lifetime alcohol consumption, and use of nonsteroidal anti-inflammatory drugs and statins (ie, model 1), and (2) additional adjustment for initiation of chemo(radio)therapy (ie, model 2). The covariates were incorporated into the models as categorical variables, as listed in supplemental eTable 1, available with this article at JNCCN.org. We assessed the proportional hazards assumption for all covariates by adding timedependent interaction terms to the covariates and

\section{Table 1. Association of Overall Comorbidity With Survival Outcomes}

\begin{tabular}{|c|c|c|c|c|c|c|c|}
\hline & $\begin{array}{c}\text { At Risk } \\
\mathbf{n}\end{array}$ & $\begin{array}{c}\text { Events } \\
n\end{array}$ & $\mathrm{HR}^{\mathrm{a}}(95 \% \mathrm{Cl})^{\mathrm{b}}$ & $\operatorname{HR}^{\mathrm{c}}(95 \% \mathrm{Cl})^{\mathrm{b}}$ & $\begin{array}{c}\text { Events } \\
n\end{array}$ & $\operatorname{HR}^{\mathrm{a}}(95 \% \mathrm{Cl})^{\mathrm{b}}$ & $\mathrm{HR}^{\mathrm{c}}(95 \% \mathrm{Cl})^{\mathrm{b}}$ \\
\hline \multicolumn{2}{|c|}{ CRC $(N=4,602)$} & \multicolumn{4}{|c|}{ Overall Survival } & \multicolumn{2}{|c|}{ CSS } \\
\hline $\mathrm{CCl} 1$ & 869 & 365 & $1.25(1.10-1.42)$ & $1.23(1.08-1.39)$ & 192 & $1.05(0.89-1.24)$ & $1.04(0.88-1.23)$ \\
\hline $\mathrm{CCl} 2$ & 620 & 285 & $1.53(1.34-1.76)$ & $1.51(1.32-1.74)$ & 142 & $1.30(1.08-1.57)$ & $1.29(1.07-1.55)$ \\
\hline $\mathrm{CCl} \geq 3$ & & \multicolumn{4}{|c|}{ Disease-Free Survivald } & \multicolumn{2}{|c|}{ Recurrence-Free Survival $^{d}$} \\
\hline $\mathrm{CCl} O$ & 2,559 & 918 & Ref & Ref & 687 & Ref & Ref \\
\hline $\mathrm{CCl} 1$ & 851 & 375 & $1.20(1.06-1.36)$ & $1.18(1.05-1.34)$ & 217 & $1.02(0.87-1.19)$ & $1.01(0.86-1.19)$ \\
\hline $\mathrm{CCl} 2$ & 606 & 298 & $1.48(1.30-1.70)$ & $1.47(1.28-1.68)$ & 169 & $1.28(1.08-1.53)$ & $1.28(1.07-1.52)$ \\
\hline $\mathrm{CCl} 0$ & 782 & 240 & Ref & Ref & 157 & Ref & Ref \\
\hline $\mathrm{CCl} 1$ & 311 & 139 & $1.42(1.14-1.77)$ & $1.36(1.09-1.70)$ & 65 & $1.17(0.86-1.59)$ & $1.12(0.82-1.53)$ \\
\hline $\mathrm{CCl} 2$ & 225 & 106 & $1.76(1.38-2.24)$ & $1.69(1.33-2.15)$ & 47 & $1.45(1.03-2.04)$ & $1.37(0.97-1.94)$ \\
\hline \multirow[t]{2}{*}{$\mathrm{CCl} \geq 3$} & 214 & 124 & $2.40(1.89-3.04)$ & $2.29(1.80-2.90)$ & 48 & $1.55(1.09-2.20)$ & $1.51(1.06-2.15)$ \\
\hline & & & $P<.001$ & $P<.001$ & & $P=.045$ & $P=.081$ \\
\hline \multicolumn{3}{|c|}{ Left-Sided Colon Cancer $(n=1,213)$} & \multicolumn{2}{|c|}{ Overall Survival } & & \multicolumn{2}{|c|}{ CSS } \\
\hline $\mathrm{CCl} O$ & 722 & 241 & Ref & Ref & 159 & Ref & Ref \\
\hline $\mathrm{CCl} 1$ & 214 & 87 & $1.33(1.03-1.71)$ & $1.27(0.98-1.65)$ & 45 & $1.14(0.80-1.62)$ & $1.06(0.74-1.52)$ \\
\hline $\mathrm{CCl} 2$ & 152 & 67 & $1.49(1.13-1.98)$ & $1.48(1.11-1.95)$ & 35 & $1.36(0.93-2.00)$ & $1.34(0.91-1.96)$ \\
\hline \multirow[t]{2}{*}{$\mathrm{CCl} \geq 3$} & 167 & 96 & $2.27(1.78-2.89)$ & $2.29(1.79-2.92)$ & 40 & $1.73(1.22-2.47)$ & $1.79(1.25-2.56)$ \\
\hline & & & $P<.001$ & $P<.001$ & & $P=.017$ & $P=.011$ \\
\hline
\end{tabular}

$P_{\text {interaction }}$ for comorbidity and overall $(P=.685)$ and CSS survival $(P=.861)$ by tumor site.

Abbreviations: BMI, body mass index; $\mathrm{CCl}$, Charlson comorbidity index score; CRC, colorectal cancer; CSS, CRC-specific survival; HR, hazard ratio.

${ }^{a}$ Adjusted for age, age $\times \log$ (follow-up time), sex, tumor stage, tumor stage $\times \log$ (follow-up time), years of school education, tumor site, period of diagnosis, period of diagnosis $\times \log$ (follow-up time), smoking status, BMI, BMI $\times \log$ (follow-up time), lifetime physical activity, lifetime alcohol consumption, and use of nonsteroidal anti-inflammatory drugs and statins.

bBold indicates statistically significant results.

cAdditional adjustment for initiation of chemo(radio)therapy and chemo(radio)therapy $\times$ log (follow-up time).

d104 patients were excluded because they had no information on recurrence or had recurrence before the interview date.

eFrom the cecum to the transverse colon.

${ }^{f}$ From the splenic colonic flexure to the sigmoid colon. 
checking whether their effects were statistically significant. Time-dependent interaction terms (with age, tumor stage, year of diagnosis, BMI, and chemo[radio] therapy) were added to the model in case of violation of the proportional assumption. Subgroup analyses according to tumor site and stage were also performed, and stagespecific results for OS were furthermore illustrated with adjusted survival curves. We moreover investigated the associations of individual comorbidities with CRC prognosis. Results from model 1 are reported as main results and those from model 2 were used to assess potential mediating effects of chemo(radio)therapy initiation. In sensitivity analyses, we used the Fine-Gray model ${ }^{22}$ to account for non-CRC mortality (a competing event for CSS and RFS) and CRC mortality (a competing event for nCSS).

In addition to hazard ratios (HRs), we calculated age advancement periods (AAPs) to quantify "age-equivalent effects" of comorbidities following an approach that was previously introduced as "risk or rate advancement periods," ${ }^{23}$ which is increasingly used in epidemiology to quantify the age advancement of the risk of diseases for which risk increases with age. ${ }^{24-28}$ A detailed description of the calculation of AAPs is provided in supplemental eAppendix 1. In brief, AAPs are derived as ratios of the regression coefficient for the risk factor under investigation (here, CCI scores 1,2 , or $\geq 3$ vs CCI 0 ) to the regression coefficient for age (where age is included in the model as a linear term, in years). Regression coefficients from model 1 were used to derive AAPs to quantify the extent (age difference) to which worse survival rates occur earlier (at younger ages) in comorbid versus noncomorbid patients. All analyses were conducted using SAS 9.4 (SAS Institute Inc). Statistical tests were 2-sided, with $\alpha=0.05$.

\section{Results}

\section{Characteristics of Study Participants}

Of 4,916 patients with CRC diagnosed in 2003-2014, 4,829 underwent CRC surgery and 4,811 survived for $\geq 1$ month. Of these, those with missing data on any of the covariates of interest were excluded $(n=209)$,

\section{Table 2. AAPs for Overall Comorbidity and Survival Outcomes}

\begin{tabular}{|c|c|c|c|c|}
\hline \multirow[b]{2}{*}{ Outcome } & \multicolumn{2}{|c|}{ All Stages } & \multicolumn{2}{|c|}{ Stages I-III } \\
\hline & $\operatorname{HR}^{a}(95 \% \mathrm{Cl})^{b}$ & $\operatorname{AAP}^{a}(95 \% \mathrm{Cl})^{\mathrm{b}, c}$ & $\operatorname{HR}^{\mathrm{a}}(95 \% \mathrm{Cl})^{\mathrm{b}}$ & $\operatorname{AAP}^{\mathrm{a}}(95 \% \mathrm{Cl})^{\mathrm{b}, \mathrm{c}}$ \\
\hline \multicolumn{5}{|c|}{ Overall survival } \\
\hline $\mathrm{CClO}$ & Ref & Ref & Ref & Ref \\
\hline $\mathrm{CCl} 1$ & $1.25(1.10 ; 1.42)$ & $5.02(1.90 ; 8.14)$ & $1.43(1.23 ; 1.66)$ & $6.01(3.13 ; 8.89)$ \\
\hline $\mathrm{CCl} 2$ & $1.53(1.34 ; 1.76)$ & $9.70(6.12 ; 13.28)$ & $1.67(1.43 ; 1.96)$ & 8.67 (5.51; 11.83) \\
\hline $\mathrm{CCl} \geq 3$ & $2.30(1.99 ; 2.66)$ & $18.86(14.42 ; 23.30)$ & $2.76(2.35 ; 3.26)$ & $17.48(13.54 ; 21.42)$ \\
\hline \multicolumn{5}{|c|}{ CRC-specific survival } \\
\hline $\mathrm{CCl} O$ & Ref & Ref & Ref & Ref \\
\hline $\mathrm{CCl} 1$ & $1.05(0.89 ; 1.24)$ & $2.11(-5.21 ; 9.43)$ & $1.25(1.00 ; 1.57)$ & $7.99(-0.86 ; 16.84)$ \\
\hline $\mathrm{CCl} 2$ & $1.30(1.08 ; 1.57)$ & $11.53(2.57 ; 20.49)$ & $1.42(1.11 ; 1.80)$ & $12.11(2.14 ; 22.08)$ \\
\hline $\mathrm{CCl} \geq 3$ & $1.56(1.26 ; 1.93)$ & $19.07(7.80 ; 30.34)$ & 1.94 (1.47; 2.55) & $24.26(10.35 ; 38.17)$ \\
\hline \multicolumn{5}{|c|}{ Non-CRC-specific survival } \\
\hline $\mathrm{CCl} O$ & Ref & Ref & Ref & Ref \\
\hline $\mathrm{CCl} 1$ & $1.70(1.40 ; 2.07)$ & 5.87 (3.32; 8.42) & $1.63(1.33 ; 2.00)$ & $5.12(2.65 ; 7.59)$ \\
\hline $\mathrm{CCl} 2$ & $1.98(1.60 ; 2.44)$ & 7.58 (4.81; 10.35) & $1.93(1.56 ; 2.38)$ & $6.89(4.22 ; 9.56)$ \\
\hline $\mathrm{CCl} \geq 3$ & $3.62(2.94 ; 4.45)$ & $14.50(11.29 ; 17.71)$ & $3.54(2.87 ; 4.37)$ & $13.51(10.44 ; 16.58)$ \\
\hline \multicolumn{5}{|c|}{ Disease-free survival } \\
\hline $\mathrm{CCl} 0$ & Ref & Ref & Ref & Ref \\
\hline $\mathrm{CCl} 1$ & $1.20(1.06 ; 1.36)$ & $5.46(1.45 ; 9.47)$ & $1.33(1.15 ; 1.54)$ & $6.49(2.74 ; 10.24)$ \\
\hline $\mathrm{CCl} 2$ & $1.48(1.30 ; 1.70)$ & $11.68(6.97 ; 16.39)$ & $1.58(1.35 ; 1.84)$ & $10.31(6.11 ; 14.51)$ \\
\hline $\mathrm{CCl} \geq 3$ & $2.03(1.77 ; 2.35)$ & $21.01(15.14 ; 26.88)$ & $2.44(2.08 ; 2.87)$ & $20.48(15.08 ; 25.88)$ \\
\hline
\end{tabular}

Abbreviations: $\mathrm{AAP}$, age advancement period (in years); $\mathrm{BMI}$, body mass index; $\mathrm{CCl}$, Charlson comorbidity index score; CRC, colorectal cancer; HR, hazard ratio. aAdjusted for age, age $\times \log$ (follow-up time), sex, tumor stage, tumor stage $\times$ log (follow-up time), years of school education, tumor site, period of diagnosis, period of diagnosis $\times \log$ (follow-up time), smoking status, BMI, BMI $\times \log$ (follow-up time), lifetime physical activity, lifetime alcohol consumption, and use of nonsteroidal anti-inflammatory drugs and statins.

bold indicates statistically significant results.

"Age was included in the model as a linear term and "age $\times \log$ (follow-up time)" was removed from the model. 
resulting in a total of 4,602 patients included in the main analysis (Figure 1). We excluded 104 patients from the analyses of recurrence-related outcomes because they had recurrence before the interview date. A total of 1,807 (39\%) deaths occurred during a median follow-up period of 5.1 years, of which 1,044 (58\%) were caused by CRC.

Descriptive statistics of the 4,602 patients are summarized in supplemental eTables 2 and 3. More than $43 \%$ of the patients had CCI $\geq 1$ (eTable 2). The 2 most common comorbidities were various cardiovascular diseases (CVDs; $18 \%$ overall) and diabetes (16\%). Median age of the participants was 69 years. Comorbidity was particularly common in men, older and underweight/obese patients, former smokers, those recently diagnosed, those with right-sided colon cancer and stage I-II disease, and nonrecipients of chemo(radio)therapy (supplemental eTable 3).

\section{Comorbidity and CRC Prognosis}

Tables 1 and 2 show adjusted HRs for the associations of overall comorbidity and CRC prognosis. HRs for CCI scores 1,2 , and $\geq 3$, compared with CCI 0 , were $1.25,1.53$, and $2.30(P<.001)$ for OS, 1.05, 1.30, and $1.56(P<.001)$ for CSS, 1.20, 1.48, and $2.03(P<.001)$ for DFS, and 1.70, 1.98, and $3.62(P<.001)$ for nCSS. The corresponding AAP estimates were 5.0, 9.7, and 18.9 years for all-cause mortality, 2.1, 11.5, and 19.1 years for CRC-specific mortality, 5.5, 11.7, and 21.0 years for worse DFS, and $5.9,7.6$, and 14.5 years for non-CRC mortality (Table 2). Noncomorbid patients aged 70 years, for example, had similar OS rates as 65-, 60-, and 51-year-old patients with CCI scores 1, 2, and $\geq 3$, respectively (Figure 2). Compared with patients with CCI 0 , those with CCI scores 2 and $\geq 3$ had $28 \%$ and $37 \%$ significantly poorer RFS, respectively. In sensitivity analyses that accounted for competing events in the associations of comorbidity

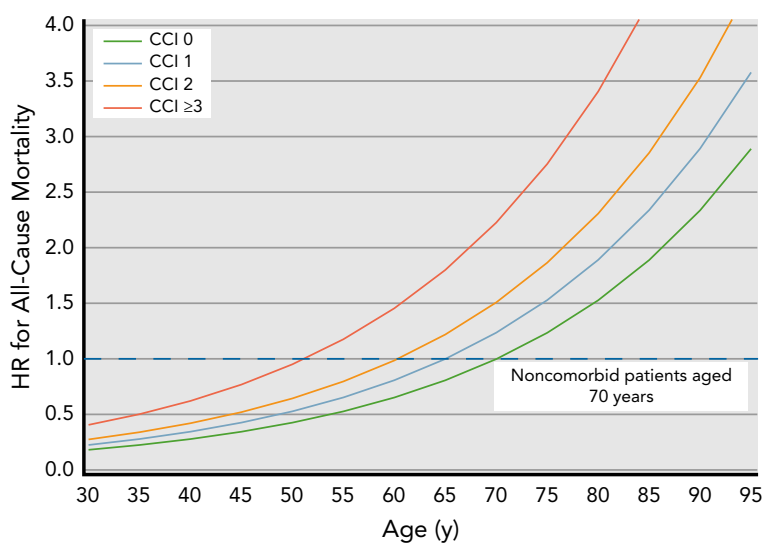

Figure 2. Age-equivalent effect of comorbidities on all-cause mortality.

Abbreviations: $\mathrm{CCl}$, Charlson comorbidity index score; $\mathrm{HR}$, hazard ratio. with CSS, RFS, and non-CRC mortality, HRs were attenuated (supplemental eTable 4). Supplemental eTable 1 shows adjusted HRs for the associations of the covariates adjusted for in the multivariable models with OS and CSS.

\section{Subgroup Analyses by Tumor Site and Stage}

Comorbidity was associated with poorer OS and CSS in all tumor sites, with comparable HRs (Table 1). The

\begin{tabular}{|c|c|c|c|}
\hline & \multicolumn{3}{|c|}{ All Stages } \\
\hline & $\begin{array}{c}\text { At Risk } \\
\mathbf{n}\end{array}$ & $\begin{array}{c}\text { Events } \\
n\end{array}$ & $\mathrm{HR}^{\mathrm{a}}(95 \% \mathrm{Cl})^{\mathrm{b}}$ \\
\hline \multicolumn{4}{|c|}{ Right-sided colon cancer $(n=1,509)^{c}$} \\
\hline $\mathrm{CCl} O$ & 771 & 183 & Ref \\
\hline $\mathrm{CCl} 1$ & 307 & 73 & $1.07(0.80-1.42)$ \\
\hline $\mathrm{CCl} 2$ & 220 & 57 & $1.43(1.05-1.96)$ \\
\hline \multirow[t]{2}{*}{$\mathrm{CCl} \geq 3$} & 211 & 53 & $1.25(0.90-1.73)$ \\
\hline & & & $P=.124$ \\
\hline \multicolumn{4}{|c|}{ Left-sided colon cancer $(n=1,181)^{d}$} \\
\hline $\mathrm{CCl} O$ & 701 & 187 & Ref \\
\hline $\mathrm{CCl} 1$ & 211 & 52 & $1.06(0.77-1.47)$ \\
\hline $\mathrm{CCl} 2$ & 147 & 39 & $1.32(0.92-1.89)$ \\
\hline \multirow[t]{2}{*}{$\mathrm{CCl} \geq 3$} & 122 & 34 & $1.53(1.02-2.30)$ \\
\hline & & & $P=.128$ \\
\hline \multicolumn{4}{|c|}{ Rectal and rectosigmoidal cancer $(n=1,808)^{e}$} \\
\hline $\mathrm{CClO}$ & 1,073 & 317 & Ref \\
\hline $\mathrm{CCl} 1$ & 333 & 92 & $1.02(0.80-1.29)$ \\
\hline $\mathrm{CCl} 2$ & 239 & 73 & $1.23(0.95-1.61)$ \\
\hline \multirow[t]{2}{*}{$\mathrm{CCl} \geq 3$} & 163 & 46 & $1.55(1.11-2.16)$ \\
\hline & & & $P=.394$ \\
\hline \multicolumn{4}{|c|}{ Rectal cancer only $(n=1,569)$} \\
\hline $\mathrm{CCl} O$ & 932 & 260 & Ref \\
\hline $\mathrm{CCl} 1$ & 299 & 81 & $1.02(0.78-1.32)$ \\
\hline $\mathrm{CCl} 2$ & 201 & 65 & $1.32(1.00-1.75)$ \\
\hline \multirow[t]{2}{*}{$\mathrm{CCl} \geq 3$} & 137 & 43 & $1.75(1.23-2.48)$ \\
\hline & & & $P=.006$ \\
\hline
\end{tabular}

$P_{\text {interaction }}=.841$ for tumor site.

Abbreviations: BMI, body mass index; $\mathrm{CCl}$, Charlson comorbidity score; $\mathrm{HR}$ hazard ratio.

${ }^{a}$ Adjusted for age, age, sex, years of school education, tumor stage, tumor stage $\times \log$ (follow-up time), period of diagnosis, period of diagnosis $\times \log$ (follow-up time), smoking status, BMI, BMI $\times$ log (follow-up time), lifetime physical activity, lifetime alcohol consumption, and use of nonsteroidal antiinflammatory drugs and statins.

${ }^{\mathrm{b} B o l d}$ indicates statistically significant results.

cFrom cecum to the transverse colon; 23 patients were excluded due to lack of information on recurrence or had recurrence before the interview date. ${ }^{d}$ From the splenic colonic flexure to the sigmoid colon; 32 patients were excluded due to lack of information on recurrence or had recurrence before the interview date.

e49 patients were excluded due to lack of information on recurrence or had recurrence before the interview date. 
association of comorbidity with RFS, however, seemed pronounced in patients with rectal cancer (Table 3). In stage-specific analyses (Table 4 and Figure 3), comorbidity was associated with decreased OS and CSS in patients with stage I-III disease only. HRs for both OS and CSS decreased steadily with increasing stage, whereas comorbidity was associated with increased non-CRC mortality in all stages, and HRs increased with increasing stage (Table 4). Significant interaction between comorbidity and stage was observed for OS $\left(P_{\text {interaction }}<.001\right)$. When we restricted our analyses to stage I-III, the associations of comorbidity with the investigated outcomes were stronger than those reported for all stages, but the AAP estimates were mostly comparable (Table 2 ).

\section{Subgroup Analyses by Individual Comorbidities}

Table 5 summarizes the associations of individual comorbidities with survival outcomes, overall and restricted to patients with stage I-III. Heart failure, renal disease, diabetes, and other cancers were consistently associated with decreased OS. Comorbidities that had the most significant impact on OS were renal disease and heart failure; each had an AAP estimate of approximately
20 years. Renal disease, heart failure, myocardial infarction (stage I-III only), and other cancers were associated with poorer CSS. Heart failure, peripheral vascular disease, stroke, renal disease, diabetes, and other cancers were associated with increased non-CRC mortality.

\section{Discussion}

We aimed to thoroughly evaluate the impact of comorbidities on CRC prognosis. Comorbidity was associated with substantially poorer prognosis, especially in patients with stage I-III disease. Besides the conventional quantification of comorbidity effects by HRs, we also calculated AAPs to estimate the "age-equivalent effects" of comorbidity in CRC prognosis. Patients with CCI scores of 1,2 , and $\geq 3$ experienced the same levels of all-cause mortality as noncomorbid patients aged 5, 10, and 19 years older, respectively.

The prevalence of comorbidities in our study (43\%) is higher than reported in a study from Japan $(25 \%)^{14}$ but lower than an estimate from the United States (58\%) in patients with comparable age. ${ }^{29}$ In particular, CVDs, diabetes, chronic obstructive pulmonary disease, and renal disease are higher in our study than in Japan but

Table 4. Associations of Overall Comorbidity With Survival Outcomes, Stratified by Tumor Stage

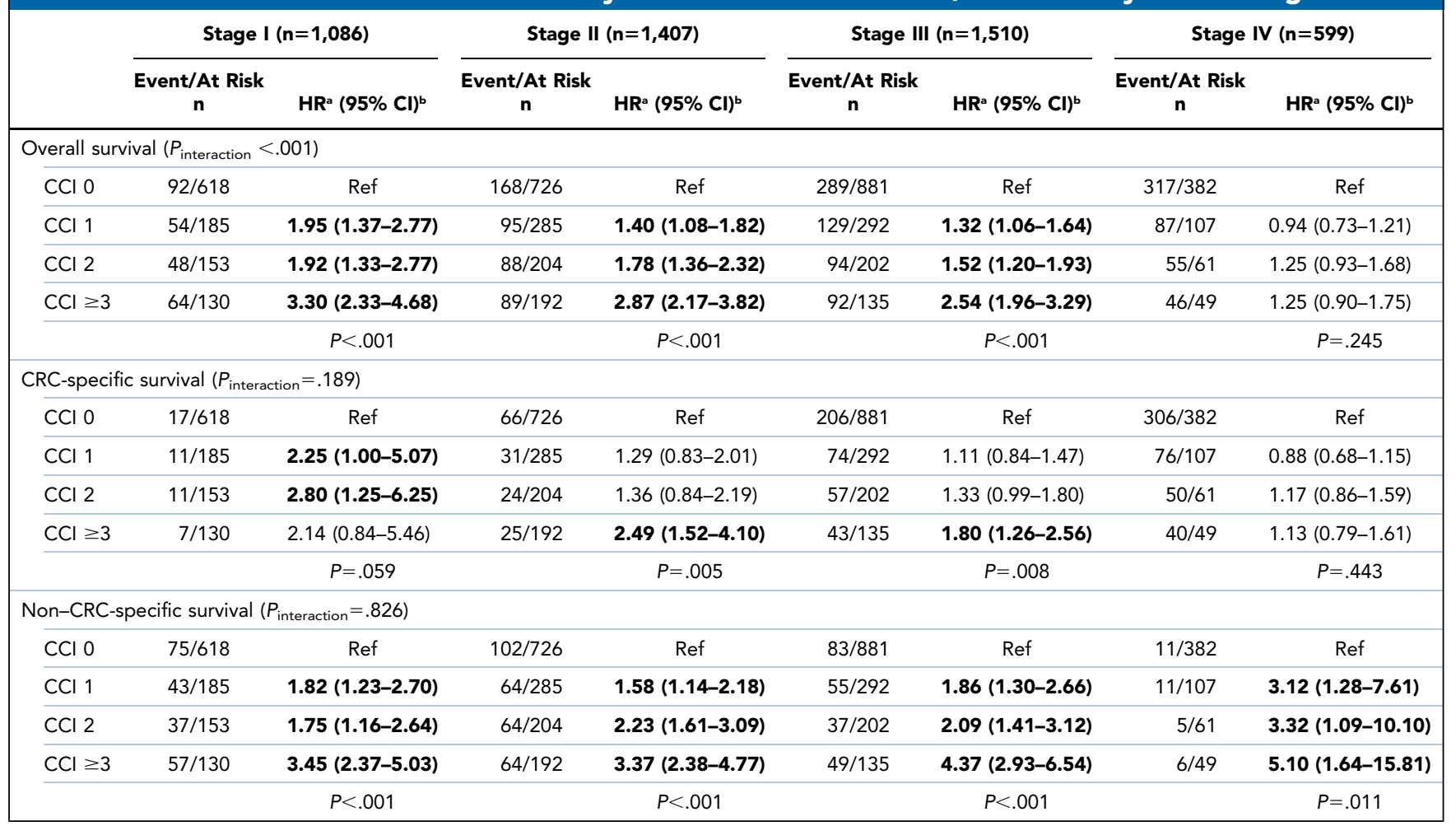

Abbreviations: $\mathrm{BMI}$, body mass index; $\mathrm{CCl}$, Charlson comorbidity index score; $\mathrm{CRC}$, colorectal cancer; $\mathrm{HR}$, hazard ratio.

aAdjusted for age, age $\times \log$ (follow-up time), sex, years of school education, tumor site, year of diagnosis, period of diagnosis $\times$ log (follow-up time), smoking status, BMI, BMI $\times \log$ (follow-up time), lifetime physical activity, lifetime alcohol consumption, and use of nonsteroidal anti-inflammatory drugs and statins.

${ }^{b}$ Bold indicates statistically significant results. 
A

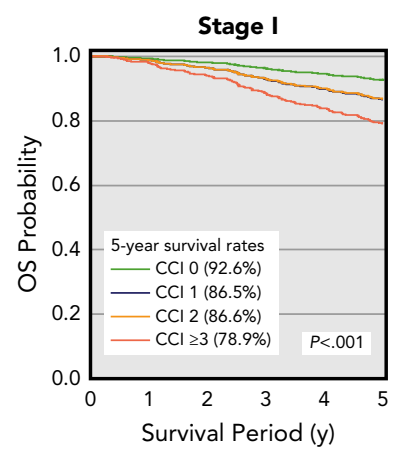

C

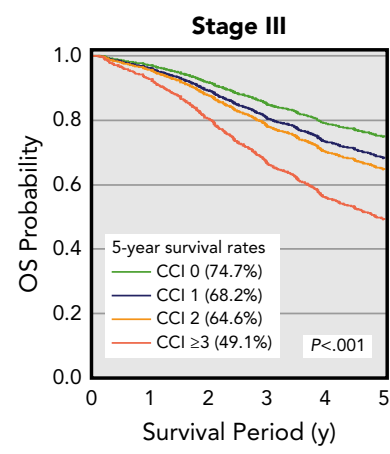

B

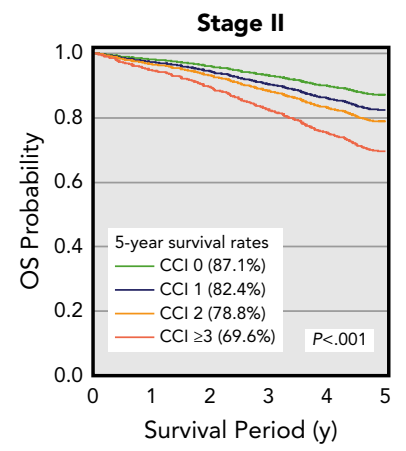

D

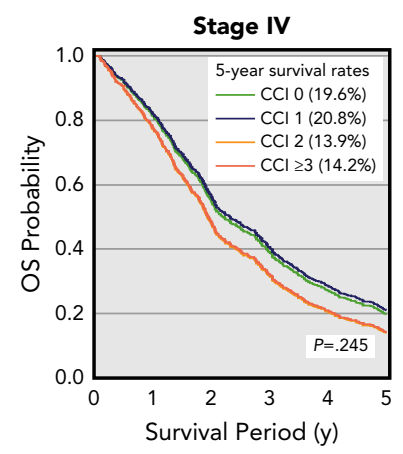

Figure 3. Adjusted survival curves for comorbidity and colorectal cancer prognosis by tumor stage: (A) I, (B) II, (C) III, and (D) IV.

Abbreviations: $\mathrm{CCl}$, Charlson comorbidity index score; OS, overall survival.

lower than in the United States. These variations might reflect differences in assessment of comorbidities across countries. Several previous studies have investigated the effect of overall comorbidity on OS or CSS. ${ }^{5-16,30,31}$ Most found poorer prognosis in comorbid patients with CRC. However, many were small in size $e^{6,8,10,30}$ and could not adjust for stage. ${ }^{7,9,11}$ Our study, which addressed these limitations, showed even shorter OS and CSS in comorbid patients. In contrast to some studies that showed no significant association for CSS in comorbid patients, ${ }^{12,14,16,30}$ we found a significant decrease in CSS also, even after accounting for competing events. Binary grouping of CCI score $(\geq 1 \text { vs } 0)^{14}$ or small sample size ${ }^{30}$ might explain why some of the previous studies found no significant association for CSS. Our estimates are comparable to those from a meta-analysis of 5 cohort studies, which observed a $41 \%$ and $103 \%$ increased allcause mortality in patients with CRC and CCI scores of 1 to 2 and $\geq 3$ compared with patients with a CCI score of 0 , respectively. ${ }^{32}$ Evidence regarding to what extent comorbidity impacts non-CRC mortality is limited..$^{33}$ In our study, comorbidity was associated with increased non-CRC mortality, and furthermore, HRs were higher than those of OS and CSS, suggesting that comorbidity affects prognosis in patients with CRC

mainly through non-CRC deaths (presumably directly comorbidity-related).

Previous evidence on whether the effect of comorbidity on CRC prognosis varies by tumor stage has been inconclusive. Results from some studies suggested that the prognostic impact of comorbidity decreases with increasing stage. ${ }^{5,14,15,29}$ Our study confirmed this trend and found no association in patients with stage IV CRC. Patients with stage IV disease have very poor survival, with death almost exclusively being due to the metastasized tumor itself. It is, therefore, plausible that the additional impact of comorbidity on prognosis in these patients may be very small. Conversely, for nonCRC mortality, the effect of comorbidity increased with increasing tumor stage. Although this has not been investigated previously, patients with advanced-stage disease might receive more aggressive treatments and thus have increased risk of adverse effects and complications, which could increase noncancer mortality.

Evidence on the impact of comorbidity on recurrencerelated outcomes is sparse. The few available studies assessed DFS only and found significantly shorter DFS in comorbid patients with CRC. ${ }^{14,31}$ We evaluated to what extent comorbidity impacts RFS, overall and in subgroups according to tumor site. We observed significantly poorer RFS in moderately and severely comorbid patients and stronger associations in patients with rectal cancer. Reasons for this differential impact of comorbidity are unclear and call for further investigation into whether comorbidities affect therapeutic response at specific tumor sites or affect tumor biology, as results from a study suggested that comorbidities could accelerate CRC progression. ${ }^{34}$ Evidence showing that rightsided CRC has poorer tumor features could also play a role, ${ }^{35}$ as our data showed pronounced impact of comorbidity in tumor stages and sites with good prognosis.

Previous studies have shown that clusters of individual comorbidities impact CRC prognosis differently. ${ }^{30,33,36}$ We found renal disease to be the comorbidity with the strongest impact on CRC prognosis, followed by heart failure, and each advanced all-cause mortality by approximately 20 years. Renal disease includes end-stage renal disease, which is a contraindication of administration of chemo(radio)therapy according to the S3 guideline in Germany. ${ }^{37}$ Renal disease also mostly results from complications of debilitating chronic diseases, including heart failure and diabetes, ${ }^{38}$ and could thus represent accumulation of effects of several severe comorbidities. These factors might explain why it had a stronger prognostic impact than CVDs and other comorbidities.

Our study is the first to quantify the "age-equivalent effects" of comorbidities in CRC prognosis. Our estimates of AAPs, which range from approximately 2 to 6 years 
Table 5. Associations of Individual Comorbidities With Survival Outcomes

\begin{tabular}{|c|c|c|c|c|c|c|c|}
\hline & $\begin{array}{l}\text { At Risk } \\
n\end{array}$ & \multicolumn{2}{|c|}{ Overall Survival } & \multicolumn{2}{|r|}{ CSS } & \multicolumn{2}{|c|}{ Non-CSS } \\
\hline No comorbidity & 2,607 & 866 & Ref & 595 & Ref & 271 & Ref \\
\hline MI only & 97 & 41 & $1.27(0.91-1.77)$ & 25 & $1.19(0.78-1.81)$ & 16 & $1.43(0.86-2.38)$ \\
\hline Stroke only & 87 & 39 & $1.57(1.12-2.18)$ & 16 & $1.24(0.75-2.07)$ & 23 & $1.78(1.14-2.77)$ \\
\hline COPD only & 151 & 51 & $1.09(0.82-1.46)$ & 29 & $0.98(0.67-1.43)$ & 22 & $1.31(0.84-2.04)$ \\
\hline Renal disease only & 71 & 37 & $2.14(1.53-3.00)$ & 20 & $1.91(1.21-3.00)$ & 17 & $2.31(1.39-3.85)$ \\
\hline $\begin{array}{l}\text { Mild liver disease } \\
\text { only }\end{array}$ & 118 & 34 & $1.02(0.72-1.44)$ & 19 & $0.88(0.55-1.40)$ & 15 & $1.19(0.70-2.00)$ \\
\hline No comorbidity & 2,225 & 549 & Ref & 289 & Ref & 260 & Ref \\
\hline MI only & 83 & 32 & $1.67(1.13-2.45)$ & 16 & $1.79(1.03-3.10)$ & 16 & $1.55(0.93-2.58)$ \\
\hline Heart failure only & 43 & 29 & $1.91(1.28-2.85)$ & 12 & $2.03(1.09-3.75)$ & 17 & $1.95(1.16-3.29)$ \\
\hline PVD only & 96 & 27 & $1.26(0.85-1.87)$ & 13 & $1.09(0.62-1.91)$ & 14 & $1.61(0.93-2.79)$ \\
\hline Stroke only & 78 & 31 & $1.36(0.93-1.98)$ & 10 & $1.01(0.53-1.93)$ & 21 & $1.60(1.01-2.53)$ \\
\hline COPD only & 134 & 39 & $1.29(0.93-1.80)$ & 17 & $1.23(0.75-2.02)$ & 22 & $1.36(0.88-2.12)$ \\
\hline Renal disease only & 62 & 28 & $2.00(1.35-2.95)$ & 12 & $1.80(1.00-3.25)$ & 16 & $2.21(1.30-3.73)$ \\
\hline $\begin{array}{l}\text { Mild liver disease } \\
\text { only }\end{array}$ & 111 & 30 & $1.14(0.79-1.66)$ & 15 & $1.04(0.61-1.75)$ & 15 & $1.21(0.72-2.05)$ \\
\hline
\end{tabular}

Abbreviations: BMI, body mass index; COPD, chronic obstructive pulmonary disease; CRC, colorectal cancer; CSS, CRC-specific survival; HR, hazard ratio; MI, myocardial infarction; PVD, peripheral vascular disease.

aAdjusted for age, age $\times \log$ (follow-up time), sex, tumor stage, tumor stage $\times$ log (follow-up time), years of school education, tumor site, period of diagnosis, period of diagnosis $\times \log$ (follow-up time), smoking status, BMI, BMI $\times \log$ (follow-up time), lifetime physical activity, lifetime alcohol consumption, and use of nonsteroidal anti-inflammatory drugs and statins.

${ }^{b}$ Bold indicates statistically significant results.

for patients with CCI score of 1 to approximately 14 to 21 years for patients with CCI score $\geq 3$, show how comorbidities strongly impact CRC prognosis. For example, patients aged 70 years without comorbidities had a similar OS rate as 51 -year-old patients with $\mathrm{CCI} \geq 3$. This underlines the important role of comorbidities in the prediction of prognosis and in therapeutic decisions, in addition to age and tumor characteristics. Despite the strong effect of comorbidities on CRC prognosis, prognostic tools still focus on tumor characteristics only. ${ }^{39,40}$ Further studies using this concept could provide useful evidence for enhanced treatment of comorbid patients and on the need to incorporate comorbidities into nomograms for enhanced prediction of CRC prognosis. Future studies should also evaluate "ageequivalent effects" of other relevant clinicopathologic factors in CRC prognosis.
Several possible mechanisms exist through which comorbidities might affect CRC prognosis. Severe comorbidities could obscure CRC signs, leading to late diagnosis and worse outcomes. ${ }^{41,42}$ Also, despite the established benefits of neoadjuvant and adjuvant treatments, comorbid patients receive such treatments less often because of potentially increased risk of chemotoxicities. ${ }^{12,29,30}$ The associations in our study, however, persisted after adjusting for initiation of chemo(radio)therapy, suggesting that this mechanism might play a minor role. Lastly, diagnosis of CRC, like other cancer diagnoses, could lead to reduced adherence to treatment regimen for long-term conditions. ${ }^{43}$ Medical care for patients with cancer might therefore benefit from more comprehensive, personalized consideration of both cancer and patient characteristics, including comorbidities. 
Our study has limitations despite its unique strengths. Although we made extensive efforts to comprehensively include all patients across the study region, approximately $50 \%$ of the eligible patients were recruited. There was also an age gradient, with higher recruitment rates at younger ages. However, we did not set an upper age limit, which has merits when aiming to assess the impact of comorbidities. Nevertheless, the most comorbid patients who would not be able to actively participate in a study requiring an interview of approximately 1 hour are most likely underrepresented, which limited our ability to assess the effects of most severe comorbidities. Our results might therefore be less generalizable to populations with severe comorbidities. Although we adjusted for a large number of confounding factors, potential residual confounding cannot be excluded, which might affect the accuracy of our AAP estimates. We used comorbidities documented in medical records only for our analyses, because data on self-reported comorbidities were not complete. Comorbidity status could also change with cancer progression or aging, but, like previous studies, its impact could only be evaluated with baseline data in our study. The resulting inaccuracy of comorbidity classification most likely has led to underestimation of comorbidity effects.

\section{Conclusions}

In the era of personalized oncology, patient characteristics often receive less attention as prognostic factors but could be equally as important as tumor characteristics in the enhanced personalized care of patients with CRC. Our findings corroborate and expand prior evidence showing that comorbidities are important prognostic characteristics that require careful consideration in CRC care. Comorbid patients at substantially younger ages experience comparable survival rates to older patients without comorbidity. This first derivation of age-advancement periods may enhance the empirical basis for treatment decisions in comorbid patients and highlight the need to incorporate comorbidities into prognostic nomograms for CRC.

\section{Acknowledgments}

We wish to thank Ute Handte-Daub, Ansgar Brandhorst, and Petra Bächer for their excellent technical assistance. We are particularly grateful to the study participants and interviewers who assisted in the data collection. We also gratefully appreciate the cooperation of the following clinics and institutions: Chirurgische Universitätsklinik Heidelberg, Klinik am Gesundbrunnen Heilbronn, St. Vincentiuskrankenhaus Speyer, St. Josefskrankenhaus Heidelberg, Chirurgische Universitätsklinik Mannheim, Diakonissenkrankenhaus Speyer, Krankenhaus Salem Heidelberg, Kreiskrankenhaus Schwetzingen, St. Marienkrankenhaus Ludwigshafen, Klinikum Ludwigshafen, Stadtklinik Frankenthal, Diakoniekrankenhaus Mannheim, Kreiskrankenhaus Sinsheim, Klinikum am Plattenwald Bad Friedrichshall, Kreiskrankenhaus Weinheim, Kreiskrankenhaus Eberbach, Kreiskrankenhaus Buchen, Kreiskrankenhaus Mosbach, Enddarmzentrum Mannheim, Kreiskrankenhaus Brackenheim, and Cancer Registry of Rhineland-Palatinate, Mainz.

Submitted February 1, 2019; accepted for publication August 9, 2019.

Author contributions: Study concept and design: Boakye, Walter, Jansen, Hoffmeister, Brenner. Data acquisition and coordination: Boakye, Walter, Jansen, Chang-Claude, Hoffmeister, Brenner. Data analysis and interpretation: Boakye, Walter, Brenner. Drafting of manuscript: Boakye, Walter, Brenner. Critical revision for important intellectual content: All authors. Approval of manuscript: All authors.

Disclosures: The authors have disclosed that they have not received any financial consideration from any person or organization to support the preparation, analysis, results, or discussion of this article.

Funding: This work was supported by grants from the German Research Council (BR 1704/6-1, BR 1704/6-3, BR 1704/6-4, CH 117/1-1), the German Federal Ministry of Education and Research (01 KH0404, 01ER0814, $01 \mathrm{ER0815}$ 01ER1505A, 01ER1505B), and the Ministry of Science, Research and Arts of Baden-Wuerttemberg

Disclosures: The funding bodies had no role in the design, the analysis or interpretation of the data, the writing of the manuscript, or the decision to publish this study.

Correspondence: Hermann Brenner, MD, MPH, Division of Clinical Epidemiology and Aging Research, German Cancer Research Center (DKFZ), Im Neuenheimer Feld 581, 69120 Heidelberg, Germany. Email: h.brenner@dkfz.de

\section{References}

1. Bray F, Ferlay J, Soerjomataram I, et al. Global cancer statistics 2018: GLOBOCAN estimates of incidence and mortality worldwide for 36 cancers in 185 countries. CA Cancer J Clin 2018;68:394-424.

2. Holleczek B, Rossi S, Domenic A, et al. On-going improvement and persistent differences in the survival for patients with colon and rectum cancer across Europe 1999-2007 - results from the EUROCARE-5 study. Eur J Cancer 2015;51:2158-2168.

3. Arnold M, Sierra MS, Laversanne M, et al. Global patterns and trends in colorectal cancer incidence and mortality. Gut 2017;66:683-691.

4. Yancik R, ErshlerW, Satariano W, et al. Report of the national institute on aging task force on comorbidity. J Gerontol A Biol Sci Med Sci 2007:62:275-280.

5. Read WL, Tierney RM, Page NC, et al. Differential prognostic impact of comorbidity. J Clin Oncol 2004;22:3099-3103.

6. Hines RB, Chatla C, Bumpers HL, et al. Predictive capacity of three comorbidity indices in estimating mortality after surgery for colon cancer. J Clin Oncol 2009;27:4339-4345

7. Iversen LH, Nørgaard M, Jacobsen J, et al. The impact of comorbidity on survival of Danish colorectal cancer patients from 1995 to 2006 - a population-based cohort study. Dis Colon Rectum 2009; 52:71-78.

8. Kristjansson SR, Jordhoy MS, Nesbakken A, et al. Which elements of a comprehensive geriatric assessment (CGA) predict post-operative complications and early mortality after colorectal cancer surgery? J Geriatr Oncol 2010;1:57-65.

9. Ostenfeld EB, Nørgaard M, Thomsen RW, et al. Comorbidity and survival of Danish patients with colon and rectal cancer from 2000-2011: a population-based cohort study. Clin Epidemiol 2013;5(Suppl 1):65-74.

10. Marventano S, Grosso G, Mistretta A, et al. Evaluation of four comorbidity indices and Charlson comorbidity index adjustment for colorectal cancer patients. Int J Colorectal Dis 2014;29:1159-1169.

11. Wu CC, Hsu TW, Chang CM, et al. Age-adjusted Charlson comorbidity index scores as predictor of survival in colorectal cancer patients who 
underwent surgical resection and chemoradiation. Medicine (Baltimore) 2015;94:e431.

12. Booth $\mathrm{CM}$, Nanji S, Wei $X$, et al. Use and effectiveness of adjuvant chemotherapy for stage III colon cancer: a population-based study. J Natl Compr Canc Netw 2016;14:47-56.

13. Nayak $P$, Luo $R$, Elting $L$, et al. Impact of rheumatoid arthritis on the mortality of elderly patients who develop cancer: a population-based study. Arthritis Care Res (Hoboken) 2017;69:75-83.

14. Yamano T, Yamauchi S, Kimura K, et al. Influence of age and comorbidity on prognosis and application of adjuvant chemotherapy in elderly Japanese patients with colorectal cancer: a retrospective multicentre study. Eur J Cancer 2017;81:90-101.

15. Brungs $D$, Aghmesheh $M$, de Souza $P$, et al. Sidedness is prognostic in locoregional colon cancer: an analysis of 9509 Australian patients. BMC Cancer 2017;17:251.

16. Parés-Badell $\mathrm{O}$, Banqué $\mathrm{M}$, Macià $\mathrm{F}$, et al. Impact of comorbidity on survival by tumour location: breast, colorectal and lung cancer (20002014). Cancer Epidemiol 2017;49:66-74.

17. Brenner $\mathrm{H}$, Chang-Claude J, Jansen L, et al. Reduced risk of colorectal cancer up to 10 years after screening, surveillance, or diagnostic colonoscopy. Gastroenterology 2014;146:709-717.

18. Hoffmeister M, Jansen $L$, Rudolph $A$, et al. Statin use and survival after colorectal cancer: the importance of comprehensive confounder adjustment. J Natl Cancer Inst 2015;107:djv045.

19. Sobin LH, Gospodarowicz MK, Wittekind C. TNM Classification of Malignant Tumours, 7th edition. New York, NY: Wiley-Blackwell; 2009: 100-105.

20. Charlson ME, Pompei P, Ales KL, et al. A new method of classifying prognostic comorbidity in longitudinal studies: development and validation. J Chronic Dis 1987;40:373-383.

21. Deyo RA, Cherkin DC, Ciol MA. Adapting a clinical comorbidity index for use with ICD-9-CM administrative databases. J Clin Epidemiol 1992 45:613-619.

22. Fine JP, Gray RJ. A proportional hazards model for the subdistribution of a competing risk. J Am Stat Assoc 1999;94:496-509.

23. Brenner H, Gefeller O, Greenland S. Risk and rate advancement periods as measures of exposure impact on the occurrence of chronic diseases. Epidemiology 1993;4:229-236.

24. Ordóñez-Mena JM, Schöttker B, Mons U, et al. Quantification of the smoking-associated cancer risk with rate advancement periods: metaanalysis of individual participant data from cohorts of the CHANCES consortium. BMC Med 2016;14:62.

25. Keil U, Liese AD, Hense HW, et al. Classical risk factors and their impact on incident non-fatal and fatal myocardial infarction and all-cause mortality in southern Germany. Results from the MONICA Augsburg cohort study 1984-1992. Monitoring Trends and Determinants in Cardiovascular Diseases. Eur Heart J 1998;19:1197-1207.

26. Ford ES, Zhao G, Tsai J, et al. Low-risk lifestyle behaviors and all-cause mortality: findings from the National Health and Nutrition Examination Survey III Mortality Study. Am J Public Health 2011;101: 1922-1929.
27. Leenders M, Sluijs I, Ros MM, et al. Fruit and vegetable consumption and mortality: European prospective investigation into cancer and nutrition. Am J Epidemiol 2013;178:590-602.

28. Raina $P$, Gilsing $A$, Freisling $H$, et al. The combined effect of cancer and cardio-metabolic conditions on the mortality burden in older adults. J Gerontol A Biol Sci Med Sci 2019;4:366-372.

29. Hahn EE, Gould MK, Munoz-Plaza CE, et al. Understanding comorbidity profiles and their effect on treatment and survival in patients with colorectal cancer. J Natl Compr Canc Netw 2018;16:23-34.

30. Sarfati $D$, Hill S, Blakely $T$, et al. The effect of comorbidity on the use of adjuvant chemotherapy and survival from colon cancer: a retrospective cohort study. BMC Cancer 2009;9:116.

31. Elliot AH, Martling A, Glimelius B, et al. Impact of pre-treatment patientrelated selection parameters on outcome in rectal cancer. Eur J Surg Oncol 2016:42:1667-1673.

32. Boakye D, Rillmann B, Walter $\mathrm{V}$, et al. Impact of comorbidity and frailty on prognosis in colorectal cancer patients: a systematic review and metaanalysis. Cancer Treat Rev 2018;64:30-39.

33. Cuthbert CA, Hemmelgarn BR, Xu Y, et al. The effect of comorbidities on outcomes in colorectal cancer survivors: a population-based cohort study. J Cancer Surviv 2018;12:733-743.

34. Erichsen R, Horváth-Puhó $\mathrm{E}$, Iversen LH, et al. Does comorbidity interact with colorectal cancer to increase mortality? A nationwide population-based cohort study. Br J Cancer 2013;109:2005-2013.

35. Petrelli F, Tomasello G, Borgonovo K, et al. Prognostic survival associated with left-sided vs right-sided colon cancer: a systematic review and meta-analysis. JAMA Oncol 2017;3:211-219.

36. Jørgensen $\mathrm{TL}$, Hallas J, Friis $\mathrm{S}$, et al. Comorbidity in elderly cancer patients in relation to overall and cancer-specific mortality. Br J Cancer 2012;106:1353-1360

37. Schmiegel W, Pox C, Reinacher-Schick A, et al. S3 guidelines for colorectal carcinoma: results of an evidence-based consensus conference on February 6/7, 2004 and June 8/9, 2007 (for the topics IV, VI and VII) Z Gastroenterol 2010;48:65-136.

38. Kazancioğlu R. Risk factors for chronic kidney disease: an update. Kidney Int Suppl (2011) 2013;3:368-371.

39. Kawai K, Sunami E, Yamaguchi H, et al. Nomograms for colorectal cancer: a systematic review. World J Gastroenterol 2015;21: 11877-11886.

40. Zhang $Z Y$, Luo $Q F$, Yin $X W$, et al. Nomograms to predict survival after colorectal cancer resection without preoperative therapy. BMC Cancer 2016;16:658.

41. Gurney J, Sarfati D, Stanley J. The impact of patient comorbidity on cancer stage at diagnosis. Br J Cancer 2015;113:1375-1380.

42. Mounce LTA, Price S, Valderas JM, et al. Comorbid conditions delay diagnosis of colorectal cancer: a cohort study using electronic primary care records. Br J Cancer 2017;116:1536-1543.

43. Stuart BC, Davidoff AJ, Erten MZ. Changes in medication management after a diagnosis of cancer among Medicare beneficiaries with diabetes. J Oncol Pract 2015;11:429-434.

See JNCCN.org for supplemental online content. 
Supplemental online content for:

\section{Magnitude of the Age Advancement Effect of Comorbidities in Colorectal Cancer Prognosis}

Daniel Boakye, MPH; Viola Walter, MSc, PhD; Lina Jansen, MSc, PhD; Uwe M. Martens, MD;

Jenny Chang-Claude, MSc, PhD; Michael Hoffmeister, MSc, PhD; and Hermann Brenner, MD, MPH

J Nat/ Compr Canc Netw 2020;18(1):59-68

eTable 1: Association of Covariates With OS and CSS

eTable 2: Definition and Frequency of Comorbidities

eTable 3: Comorbidity Scores by Sociodemographic, Lifestyle, and Tumor Characteristics

eTable 4: Associations of Overall Comorbidity With Survival Outcomes

eAppendix 1: Age Advancement Periods for Comorbidity and Survival Outcomes 


\section{eTable 1. Association of Covariates With OS and CSS}

\begin{tabular}{|c|c|c|c|c|c|}
\hline \multirow[b]{2}{*}{ Characteristic } & \multirow[b]{2}{*}{ At Risk, N } & \multicolumn{2}{|c|}{ os } & \multicolumn{2}{|c|}{ css } \\
\hline & & Events, $\mathbf{n}$ & $\mathrm{HR}^{\mathrm{a}}(95 \% \mathrm{Cl})^{\mathrm{b}}$ & Events, $n$ & $\mathrm{HR}^{\mathrm{a}}(95 \% \mathrm{Cl})^{\mathrm{b}}$ \\
\hline \multicolumn{6}{|l|}{ Sex } \\
\hline Female & 1,814 & 684 & Ref & 427 & Ref \\
\hline Male & 2,788 & 1,123 & $1.13(1.00-1.28)$ & 617 & $0.97(0.83-1.14)$ \\
\hline \multicolumn{6}{|l|}{ Age, y } \\
\hline $30-59$ & 995 & 266 & Ref & 219 & Ref \\
\hline $60-69$ & 1,392 & 471 & $1.33(1.14-1.56)$ & 308 & $1.25(1.04-1.50)$ \\
\hline $70-79$ & 1,535 & 639 & $1.83(1.57-2.15)$ & 348 & $1.58(1.31-1.91)$ \\
\hline$\geq 80$ & 680 & 431 & $3.60(3.02-4.30)$ & 169 & $2.17(1.71-2.75)$ \\
\hline \multicolumn{6}{|c|}{ Years of school education } \\
\hline$<9$ & 3,010 & 1,263 & $1.07(0.93-1.24)$ & 675 & $0.90(0.75-1.09)$ \\
\hline $9-10$ & 818 & 292 & $1.06(0.89-1.26)$ & 196 & $1.03(0.83-1.26)$ \\
\hline$>10$ & 774 & 252 & Ref & 173 & Ref \\
\hline \multicolumn{6}{|l|}{$\mathrm{BMI}, \mathrm{kg} / \mathrm{m}^{2}$} \\
\hline$<18.5$ & 90 & 44 & $1.28(0.94-1.75)$ & 26 & $1.28(0.85-1.91)$ \\
\hline $18.5-24.9$ & 1,678 & 695 & Ref & 399 & Ref \\
\hline $25-29.9$ & 1,959 & 747 & $0.89(0.80-0.99)$ & 437 & $0.98(0.85-1.13)$ \\
\hline$\geq 30$ & 875 & 321 & $0.89(0.77-1.02)$ & 182 & $0.94(0.78-1.12)$ \\
\hline \multicolumn{6}{|c|}{ Lifetime physical activity, MET-h/wk } \\
\hline Q1 (3.3-112.2) & 917 & 338 & Ref & 202 & Ref \\
\hline Q2 (112.3-161.1) & 915 & 336 & $1.03(0.89-1.21)$ & 189 & $0.98(0.80-1.21)$ \\
\hline Q3 (161.2-211.1) & 922 & 368 & $1.17(1.01-1.37)$ & 210 & $1.16(0.95-1.42)$ \\
\hline Q4 (211.2-287.5) & 929 & 348 & $1.01(0.87-1.18)$ & 199 & $1.06(0.86-1.30)$ \\
\hline Q5 (287.6-788.2) & 919 & 417 & $1.16(0.99-1.35)$ & 244 & $1.23(1.00-1.50)$ \\
\hline \multicolumn{6}{|l|}{ Smoking status } \\
\hline Never-smoker & 1,854 & 760 & Ref & 462 & Ref \\
\hline Former smoker & 2,008 & 767 & $0.89(0.80-1.00)$ & 407 & $0.84(0.73-0.97)$ \\
\hline Current smoker & 740 & 280 & $0.99(0.85-1.14)$ & 175 & $0.89(0.74-1.08)$ \\
\hline \multicolumn{6}{|c|}{ Lifetime alcohol consumption, $\mathrm{g} / \mathrm{d}$} \\
\hline None & 751 & 337 & Ref & 205 & Ref \\
\hline $\mathrm{T} 1(0.1-6.8)$ & 1,280 & 462 & $0.83(0.72-0.96)$ & 279 & $0.81(0.67-0.97)$ \\
\hline T2 (6.9-20.6) & 1,290 & 494 & $0.75(0.64-0.88)$ & 285 & $0.71(0.58-0.87)$ \\
\hline T3 (20.7-381.9) & 1,281 & 514 & $0.87(0.74-1.03)$ & 275 & $0.78(0.63-0.96)$ \\
\hline \multicolumn{6}{|l|}{ Period of diagnosis } \\
\hline $2003-2005$ & 1,195 & 609 & Ref & 334 & Ref \\
\hline 2006-2008 & 1,102 & 529 & $0.89(0.79-1.01)$ & 284 & $0.82(0.70-0.96)$ \\
\hline $2009-2011$ & 1,198 & 386 & $0.95(0.82-1.09)$ & 233 & $0.80(0.67-0.95)$ \\
\hline 2012-2014 & 1,107 & 283 & $0.81(0.69-0.95)$ & 193 & $0.72(0.59-0.87)$ \\
\hline \multicolumn{6}{|l|}{ Tumor site } \\
\hline Right colon ${ }^{c}$ & 1,532 & 609 & Ref & 317 & Ref \\
\hline Left colon ${ }^{d}$ & 1,213 & 466 & $1.03(0.91-1.16)$ & 266 & $1.03(0.87-1.22)$ \\
\hline Rectume & 1,857 & 732 & $1.17(1.03-1.33)$ & 461 & $1.24(1.04-1.47)$ \\
\hline
\end{tabular}




\section{eTable 1. Association of Covariates With OS and CSS (cont.)}

OS

CSS

\begin{tabular}{|c|c|c|c|c|c|}
\hline \multirow[b]{2}{*}{ Characteristic } & \multirow[b]{2}{*}{ At Risk, N } & & \\
\hline & & Events, $\mathbf{n}$ & $\mathrm{HR}^{\mathrm{a}}(95 \% \mathrm{Cl})^{\mathrm{b}}$ & Events, $\mathbf{n}$ & $\mathrm{HR}^{\mathrm{a}}(95 \% \mathrm{Cl})^{\mathrm{b}}$ \\
\hline \multicolumn{6}{|l|}{ Tumor stage, UICC } \\
\hline I & 1,086 & 258 & Ref & 46 & Ref \\
\hline II & 1,407 & 440 & $1.41(1.21-1.65)$ & 146 & $2.66(1.90-3.72)$ \\
\hline III & 1,510 & 604 & $2.56(2.14-3.07)$ & 380 & 8.33 (5.92-11.72) \\
\hline IV & 599 & 505 & $15.13(12.42-18.42)$ & 472 & $61.29(43.25-86.84)$ \\
\hline \multicolumn{6}{|l|}{ Treatment initiation } \\
\hline None & 2,427 & 815 & Ref & 283 & Ref \\
\hline Radiotherapy only & 77 & 32 & $0.90(0.62-1.30)$ & 19 & $0.95(0.58-1.55)$ \\
\hline Chemotherapy only & 1,311 & 661 & $0.72(0.62-0.84)$ & 532 & $0.77(0.63-0.94)$ \\
\hline Chemoradiotherapy & 787 & 299 & $0.80(0.67-0.96)$ & 210 & $0.84(0.66-1.07)$ \\
\hline
\end{tabular}

Abbreviations: BMI, body mass index; CRC, colorectal cancer; CSS, CRC-specific survival; HR, hazard ratio; $M E T$, metabolic equivalent task hour; OS, overall survival; $\mathrm{Q}$, quintile; T, tertile.

adjusted for all the variables listed in the table and comorbidity scores.

bBold indicates statistically significant results.

'From the cecum to the transverse colon.

dFrom the splenic colonic flexure to the sigmoid colon.

encluding rectosigmoidal tumor $(n=245)$. 


\section{eTable 2. Definition and Frequency of Comorbidities}

\begin{tabular}{|c|c|c|c|}
\hline Comorbidity & ICD-10 Codes & $n(\%)$ & CCl Weight \\
\hline Myocardial infarction & $121.1,121.3,121.4,121.9,122,123,125.1,125.2,125.6$ & $331(7.2)$ & 1 \\
\hline Congestive heart failure & $111.0,113.0,113.2,150,150.0,150.1,150.3,150.4,150.9$ & $164(3.6)$ & 1 \\
\hline Peripheral vascular disease & $170,171,172,173,177, \mathrm{~K} 55$ & $265(5.8)$ & 1 \\
\hline Stroke and hemi/paraplegia & & $209(4.5)$ & \\
\hline Stroke ${ }^{a}$ & G45, G46, 160-169, Z86.7 & 196 & 1 \\
\hline Hemi/Paraplegia ${ }^{a}$ & G11.4, G80, G81, G82, G83, 169.05 & 13 & 2 \\
\hline COPD & J40-J47, J60-J70, J84.1, J92, J96.1, J98.2, J98.3, 127.8, I27.9 & $339(7.4)$ & 1 \\
\hline Chronic renal disease & $\begin{array}{l}\text { N01-N05, N07, N11, N17-N19, N25, I12.0, I13.1, I13.2, Z49, } \\
\text { Z94.0, Z99.2 }\end{array}$ & $247(5.4)$ & 2 \\
\hline Chronic liver disease & & $239(5.2)$ & \\
\hline Milda & K70-K76, B18 & 238 & 1 \\
\hline Moderate-severe ${ }^{a}$ & K70.4, K71.1, K72.1, K72.9, K76.7, B15, B16, B19, Z94.4 & 1 & 3 \\
\hline Diabetes mellitus & & $746(16.2)$ & \\
\hline Without complications ${ }^{\mathrm{a}}$ & E10. $\times-E 14 . \times($ where $\times=0,1$, or 9) & 704 & 1 \\
\hline With complications ${ }^{a}$ & E10. $\times$-E14. $\times($ where $\times=2,3,4,5,6,7$, or 8$)$ & 42 & 2 \\
\hline Gastric/Duodenal ulcer & K25-K28 & $27(0.6)$ & 1 \\
\hline Rheumatoid disease & M05, M06, M08, M30-M36 & $29(0.6)$ & 1 \\
\hline Dementia & F00, F01, F02, F03, F05.1, G30, G30.9, G31.1 & $21(0.5)$ & 1 \\
\hline $\begin{array}{l}\text { Noncolorectal cancer (except basal } \\
\text { skin carcinoma) }\end{array}$ & $\begin{array}{l}\text { C00-C17, C21-C26, C30-C34, C37-C41, C43, C45-C58, } \\
\text { C60-C76, C81-C85, C88, C90-C97, Z85. } \times \text { (where } \times=0,2,3,4 \text {, } \\
5,6 \text {, or 8) }\end{array}$ & $422(9.2)$ & 2 \\
\hline \multicolumn{4}{|l|}{$\mathrm{CCl}$ score $^{\mathrm{b}}$} \\
\hline Median (range) & & $0(0-8)$ & \\
\hline 0 & & $2,607(56.6)$ & \\
\hline 1 & & $869(18.9)$ & \\
\hline 2 & & $620(13.5)$ & \\
\hline$\geq 3$ & & $506(11.0)$ & \\
\hline
\end{tabular}

Abbreviations: $\mathrm{CCl}$, Charlson comorbidity index; COPD, chronic obstructive pulmonary disease.

aAre mutually exclusive (when both were present, the one with higher $\mathrm{CCl}$ weight was considered).

bHIV/AIDS did not contribute to the overall comorbidity scoring because none of the patients had this condition. 
eTable 3. Comorbidity Scores by Sociodemographic, Lifestyle, and Tumor Characteristics

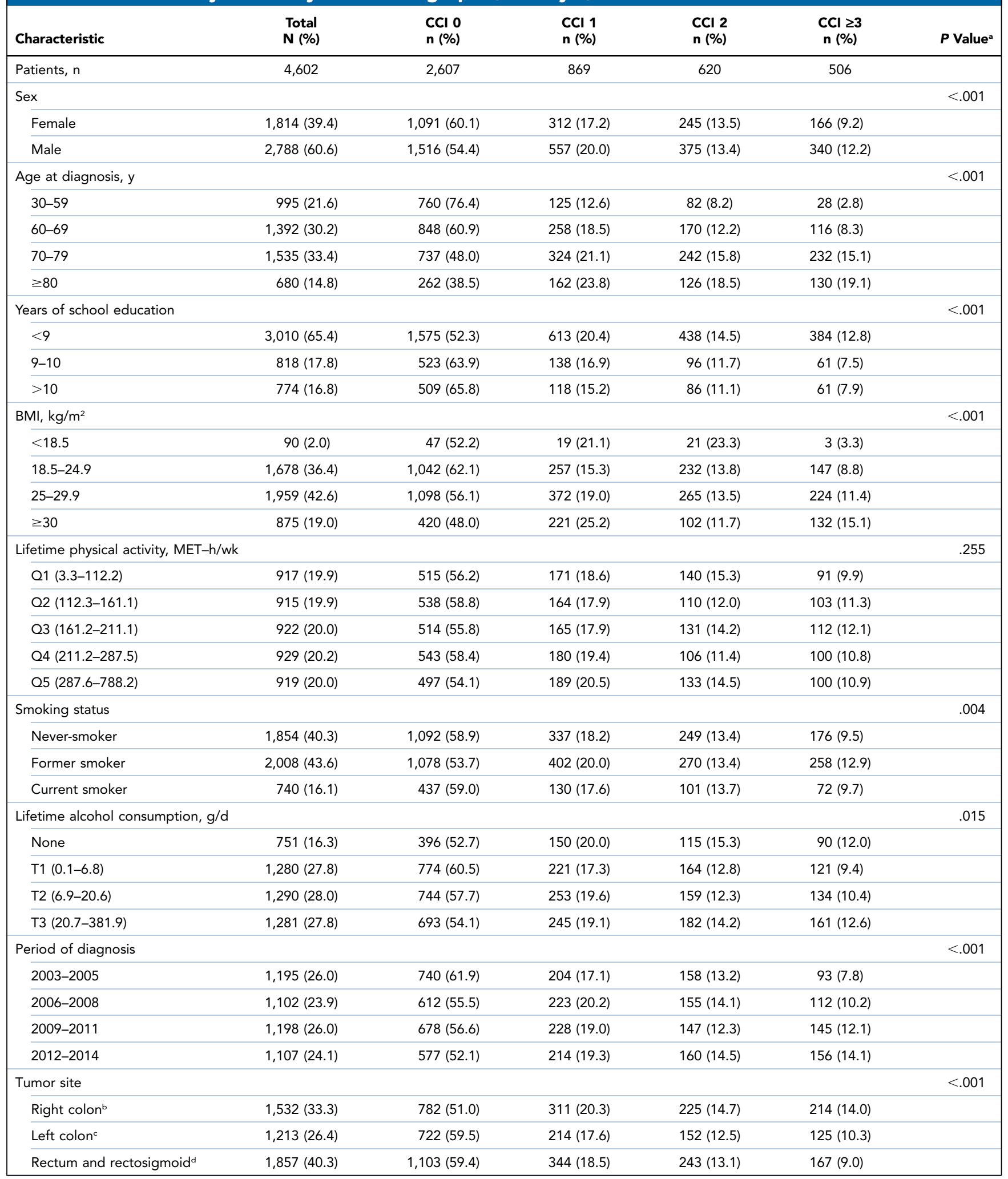

(continued on next page) 


\begin{tabular}{|c|c|c|c|c|c|c|}
\hline I & $1,086(23.6)$ & $618(56.9)$ & $185(17.0)$ & $153(14.1)$ & $130(12.0)$ & \\
\hline$\|$ & $1,407(30.6)$ & $726(51.6)$ & $285(20.3)$ & $204(14.5)$ & $192(13.6)$ & \\
\hline Treatment initiation & & & & & & $<.001$ \\
\hline None & $2,427(52.7)$ & $1,222(50.4)$ & $488(20.1)$ & $360(14.8)$ & $357(14.7)$ & \\
\hline Radiotherapy only & $77(1.7)$ & $45(58.4)$ & $16(20.8)$ & $9(11.7)$ & $7(9.1)$ & \\
\hline Chemotherapy only & $1,311(28.5)$ & $836(63.8)$ & $230(17.5)$ & $150(11.4)$ & $95(7.3)$ & \\
\hline
\end{tabular}

Abbreviations: BMI, body mass index (at diagnosis); CCl, Charlson comorbidity index score; CRC, colorectal cancer; MET, metabolic equivalent task hour; $\mathrm{Q}$, quintile; $\mathrm{T}$, tertile.

${ }^{2} P$ values were calculated using chi-square test.

bFrom the cecum to the transverse colon.

cFrom the splenic colonic flexure to the sigmoid colon.

dRectosigmoidal tumor $(n=245)$. 


\begin{tabular}{|c|c|c|}
\hline \multicolumn{3}{|c|}{$\begin{array}{l}\text { eTable 4. Associations of Overall Comorbidity } \\
\text { With Survival Outcomes }\end{array}$} \\
\hline & Cox Model ${ }^{a}$ & Fine-Gray Model ${ }^{b}$ \\
\hline & $\operatorname{HR}^{\mathrm{c}}(95 \% \mathrm{Cl})^{\mathrm{d}}$ & $\operatorname{sHR}^{c}(95 \% \mathrm{Cl})^{d}$ \\
\hline \multicolumn{3}{|c|}{ CRC-specific survival } \\
\hline $\mathrm{CClO}$ & Ref & Ref \\
\hline $\mathrm{CCl} 1$ & $1.05(0.89-1.24)$ & $1.00(0.84-1.19)$ \\
\hline $\mathrm{CCl} 2$ & $1.30(1.08-1.57)$ & $1.22(1.02-1.47)$ \\
\hline $\mathrm{CCl} \geq 3$ & $1.56(1.26-1.93)$ & $1.26(1.01-1.56)$ \\
\hline \multicolumn{3}{|c|}{ Recurrence-free survival } \\
\hline $\mathrm{CClO}$ & Ref & Ref \\
\hline $\mathrm{CCl} 1$ & $1.02(0.87-1.19)$ & $0.97(0.83-1.15)$ \\
\hline $\mathrm{CCl} 2$ & $1.28(1.08-1.53)$ & $1.22(1.03-1.45)$ \\
\hline $\mathrm{CCl} \geq 3$ & $1.37(1.13-1.67)$ & $1.18(0.97-1.43)$ \\
\hline \multicolumn{3}{|c|}{ Non-CRC-specific survival } \\
\hline $\mathrm{CClO}$ & Ref & Ref \\
\hline $\mathrm{CCl} 1$ & $1.70(1.40-2.07)$ & $1.62(1.34-1.97)$ \\
\hline $\mathrm{CCl} 2$ & $1.98(1.60-2.44)$ & $1.83(1.48-2.26)$ \\
\hline $\mathrm{CCl} \geq 3$ & $3.62(2.94-4.45)$ & $3.06(2.48-3.78)$ \\
\hline
\end{tabular}

Abbreviations: BMI, body mass index; CCl, Charlson comorbidity index score; CRC, colorectal cancer; HR; hazard ratio; sHR, subdistributional hazard ratio. aCompeting events not accounted for.

${ }^{b}$ Accounted for competing events.

cAdjusted for age, age $\times \log$ (follow-up time), sex, tumor stage, tumor stage $\times \log$ (follow-up time), years of school education, tumor site, period of diagnosis, period of diagnosis $\times \log$ (follow-up time), smoking status, BMI, BMI $\times \log$ (follow-up time), lifetime physical activity, lifetime alcohol consumption, and use of nonsteroidal anti-inflammatory drugs and statins.

Bold indicates statistically significant results. 


\section{eAppendix 1.}

\section{Age Advancement Periods for Comorbidity and Survival Outcomes}

If the regression coefficients from multivariable Cox proportional hazards models for the association of comorbidity (Charlson comorbidity index [CCI] scores 1, 2, or $\geq 3$ compared with CCI 0 ) with survival outcomes (eg, all-cause mortality) and age (linear term in years) with survival outcomes are $\beta_{\mathrm{c}}$ and $\beta_{\mathrm{a}}$, respectively;

then,

Point estimates of age advancement periods (AAP) are given as

$$
\frac{\beta c}{\beta a}, \text { and }
$$

SE of AAP are given as $\mathrm{SE}=\sqrt{\operatorname{var}(\mathrm{AAP})}$, where

$$
\operatorname{var}(A A P)=\left(\frac{1}{\beta a}\right)^{2}\left\{\operatorname{var}(\beta c)-2 *\left(\frac{\beta c}{\beta a}\right) * \operatorname{cov}(\beta c, \beta a)+\left(\frac{\beta c}{\beta a}\right)^{2} * \operatorname{var}(\beta a)\right\}
$$

$\operatorname{var}(\beta c)$ and $\operatorname{var}(\beta a)$ denote the variances of comorbidity score and age, respectively, and $\operatorname{cov}(\beta c, \beta a)$ denotes the covariance difference of comorbidity score and age

95\% CIs of AAP are given as point estimates of

$$
\mathrm{AAP} \pm 1.96 * S E
$$

\section{Reference}

1. Brenner H, Gefeller O, Greenland S. Risk and rate advancement periods as measures of exposure impact on the occurrence of chronic diseases. Epidemiology 1993;4:229-236. 